\title{
Flowering Period Variability in Relation to Seed Cotton Yield, Ginning Out Turn and Other Desirable Traits in Genetic Resources of G.hirsutum Cotton
}

\author{
Ram Awatar Meena*, Dilip Monga, Satish Kumar Sain and Shankar Lal Ahuja
}

ICAR-Central Institute for Cotton Research, Regional Station, Sirsa-125 055, Haryana, India

*Corresponding author

\begin{abstract}
A B S T R A C T
Key words

Cotton, Flower retention period, Maturity period, Yield characteristics

Article Info

Accepted:

12 September 2018 Available Online:

10 October 2018

Geographically and phenotypically diverse 860 G. hirsutum germplasm lines were evaluated under North Zone irrigated conditions of India during 2011-12 and 2012-13 for a different flower retention period, seed cotton yield and other desirable traits. The accessions initiate flowering at 60 days were having maturity period below 150 days, horizontal width less than $40 \mathrm{~cm}$, hence showed suitability for high density cropping system (HDPS) for productivity enhancement. The accessions which flowers at 80 days are found to be semi spreading in nature. Accessions which flower around at 100 days, showed the maturity period below 180 days with horizontal width between 50 and $90 \mathrm{~cm}$. Among all, the accessions which flower at 60 days was considered fit for the regions in the world having the climatic condition similar to North Zone of India. These accessions require less crop production and protection inputs than long duration cultivars, hence enhance benefit cost ratio. These also provide opportunity to include another short duration crop in the current cropping system. Further crop improvement programmes should be concentrated to develop early maturing cultivars suitable for HDPS.
\end{abstract}

\section{Introduction}

Cotton (Gossypium hirsutum L.) is one of the most important cash crops that provide fiber to the textile industries around the world. It also provides employment to millions of people for different activities such as research, seed production, marketing, industrial utilization, etc. India remains the leading country in terms of area under cotton cultivation and raw cotton production in the world. Cotton is being cultivated in around 12.2 million ha area with production of 37.7 million bales. The productivity in India (524 $\mathrm{kg}$ lint/ha) is low in comparison to a world average $(792 \mathrm{~kg} / \mathrm{ha})$ and that of Brazil $1555 \mathrm{~kg} / \mathrm{ha}$, China (1761 $\mathrm{kg} / \mathrm{ha}$ ) and USA (1008 kg/ha) (Anonymous, 2017).

In North India cotton being cultivated in around 1.544 million ha with production around 5.9 million bales and productivity 650 $\mathrm{kg} / \mathrm{ha}$ (Anonymous, 2017). The cotton varieties and hybrids commonly grown in this zone generally have high vegetative growth and maturity period 160-180 days. Among the cultivars, some begin flowering very early around 60 days after their planting in May 
while the others start flowering very late at 80 days after planting. On the other side, some cultivars keep on flowering during the entire productive period of 170 days till last week of September, while the others terminate flowering 10-15 days before the completion of productive period in the region. Henceforth, the different cotton cultivars are exposed to varying climatic/ weather conditions and require crop production and protection inputs according to their crop duration. The growth habit of the cultivars is responsible for such variation.

The flowering period is an important parameter for selecting the cultivars for appropriate region for cultivation. It also determines management practices for cultivars of shorter and longer growth cycle. The mechanism of insect resistance involves an escape mechanism by preponement of maturity. The cultivars of short flowering period complete their reproductive phase before buildup of insect population (Khadi et al., 2010). The relationship between evaporation, sunshine duration, relative humidity, surface soil temperature, and maximum air temperature were observed important climatic factors that significantly affect flowering and boll production (Zakaria et al., 2013). Cotton germplasm resources contain beneficial allelic variations that can be exploited to develop improved cultivars with desired traits. The effectiveness of selection for desired traits depends on the amount of range of variability for each parameter available in the germplasm accessions. To select the genotype with suitable flowering period, it is necessary to generate information on genetic variability in germplasm for flowering period along with higher yield potential. The variability of various yield and yield contributing traits has been studied by various workers (Hinze et al., 2011; Talib et al., 2015). However, studies for variation in flowering period in relation to seed cotton yield, ginning out turn and other desirable traits in genetic resources of $G$. hirsutum cotton is either not or meagerly available. Keeping this in view, the study focusing on variation in flowering period in relation to seed cotton yield, ginning out turn percent and other desirable traits have been carried out. Hence, a large number of geographically and phenotypically diverse germplasm lines from the National gene pool of G. hirsutum cotton were evaluated under irrigated condition of North Zone of India.

\section{Materials and Methods}

Eight hundred sixteen geographically and phenotypically diverse G. hirsutum germplasm lines were obtained from the National germplasm pool maintained at Central Institute for Cotton Research, Nagpur, India. These germplasm lines include indigenous and exotic cotton collections and were evaluated under North Zone irrigated conditions of India at Central Institute for Cotton Research, Regional Station, Sirsa, Haryana (at latitude 29.543922"N longitude 75.038995"E) during 2011-12 and 2012-13 crop seasons (April to November). To screen the lines for days of flowering, their seed cotton yield and other desirable traits. Each accession was replicate twice with two rows each and 10 dibbles per row. The accessions were sown at $67.5 \times 30 \mathrm{~cm}$ spacing adopting all recommended agronomic and plant protection measures. The field experiment was conducted in randomized block design.

Observations on flowering, yield per plant and yield contributing parameters including boll weight $(\mathrm{g})$, number of bolls per plant, number of monopodia, number of sympodia, seed index, lint index, ginning out turn percent were recorded in two replications and were analyzed statistically for range and correlation using the statistical method as described by Sheoran et al., (1998). The data were recorded 
on 10 random plants for number of bolls /plant, monopodial branches/plant, sympodial branches/plant, plant height $(\mathrm{cm})$, boll weight (g) and seed cotton yield of two rows in each replication of each germplasm line. Ginning out turn percent was estimated by weighing $\%$ amount of lint obtained from $100 \mathrm{gm}$ of seed cotton.

The accessions involved in the study were classified into four groups based on number of days to flowering. The first group involves the accessions which flowers at 60 days of the crop. Similarly, the accessions which flowers at 80 days, 100 days and 120 days were separately grouped in second, third and fourth group, respectively. In each group, the frequency of accessions, their maturity period and horizontal width or canopy diameter was estimated. The experiment was conducted in randomized block design. Statistical analysis was done using OP State software and means and Critical difference at $0.5 \%$ was estimated using analysis of variance for randomized block design (Sheoran et al., 1998)

\section{Results and Discussion}

In the present study, out of 816 number of germplasm accessions evaluated, the minimum number of accessions (58) fell into a group of flowering at 60 days. 188 accessions were observed in group of flowering at 80 days; 283 accessions in flowering at 100 days and 288 in flowering at 120 days. In the group of accessions flower at 60 days, the boll weight $(\mathrm{g})$ ranged from 1.4-3.6 g; seed cotton yield /plant from $6.6-122.7 \mathrm{~g}$; number of boll/plant from 1-40, ginning outturn $\%$ from 21.7-40.6, seed index from 6.1-11.6 g and lint index from 1-6.2. In the group of flowering at 80 days the range for boll weight ( $\mathrm{g}$ ) from 1.8$3.8 \mathrm{~g}$, seed cotton yield /plant from 5.0-167.4 $\mathrm{g}$, number of boll/plant from 1-55, ginning outturn\% from 25-40.3, seed index (g) 5.611.8 and lint index from 1-7.0 were observed.
In the third group of accessions flowering at 100 days, the range of boll weight $(\mathrm{g})$ from 1.4 to 3.8, seed cotton yield /plant from 6.2$184.8 \mathrm{~g}$, number of boll/plant from 1-75, ginning outturn $\%$ from 22.6-40.9, seed index from 5.9 to $12.0 \mathrm{~g}$ and lint index from 1.0 - 6.8 were observed. Variation in group of flowering at 120 days for boll weight from 1.8 to $4.5 \mathrm{~g}$, seed cotton yield 8.0 to 255 /plant (g), number of boll/plant 1.0-65, ginning outturn 25- $40.9 \%$, seed index 5.6 to $12.0 \mathrm{~g}$ and lint index from 1.0-6.8 (Table 1).

In the group of accessions flower at 60 days, slightly lower value of boll weight, yield per plant, number of bolls per plant, seed index and lint index were observed, but most of the accessions under this group are compact in nature with horizontal width less than $40 \mathrm{~cm}$ (Fig. 1). The maturity period of the accessions of this group ranged from 120 -180 days; however the maximum numbers of the accessions have a maturity below 150 days (Fig. 2).

In accessions of flowering at 100 days, the increase in boll weight, yield per plant, number of boll per plant were observed in comparison to accessions flower at 80 days. The maturity period of the accessions in this group ranged from 130 to more than 200 days, with majority of 150-180 days maturity (Fig. 2). The horizontal width of maximum number of accession was from 50 to $90 \mathrm{~cm}$ (Fig. 1) which indicate their spreading nature.

In each group, some of the accessions found superior for a specific trait also possessed superiority for other traits in combinations were identified. In the group of flowering at 60 days, the accession S-4727-A-1 along with superiority for boll weight $(3.58 \mathrm{~g})$ also possessed superiority for number of bolls per plant (38) (Table 1). Similarly the accession IC 358862 for boll weight (3.6 g) as well as boll number per plant (34) and the accession 
IC 359708 for ginning outturn (40\%) and lint index (5.5) was observed superior. In the group of accessions which flower at 80 days, the accession AK 32 and C 3381 showed superiority for seed cotton yield/plant 167.4 and $154 \mathrm{~g}$ as well as for number of bolls plant 54 and 55, respectively. The accession N -66 for number of bolls per plant (50) and lint index (6.7) and accession IC 356667 for ginning outturn $(40.3 \%)$ and lint index (6.6) were observed superior. In the group of accessions flowering at 120 days, the accession SA 1177 for boll weight (3.9 g) and seed index (11.1 g) and accession SV 504 for yield/plant (175 g) and boll number/plant (63) possessing the superiority (Table 1).

Out of 860 geographically and phenotypically diverse G. hirsutum cotton germplasm lines were evaluated for flowering behaviour. The accessions were divided into the four groups on the basis of flower initiation at 60, 80, 100 and 120 days where each group consisted of 58, 188, 283 and 288 accessions, respectively. Most of the yield contributing traits was found to have lower values in the accessions flower at 60 days, which gradually increased in the accessions which flower late at 80 and 100 days of crop age. After that, further increase in these traits was not observed in the accessions which flower late after 100 days, except yield in which slight improvement was observed (Table 1). However, there was significant difference in ginning out turn percentage among the groups based on flower initiation.

The accessions which flower at 60 days, were observed with a slightly lower value of yield traits, but most of the accessions of this group are compact in nature having horizontal width less than $40 \mathrm{~cm}$ (Fig. 1). Maximum numbers of accessions of this group are early in maturity around 150 days (Fig. 2). Due to these characteristics the accessions of this group were observed suitable for high density planting system. These are also suitable for situation of low input to manage biotic and abiotic stresses because of the shorter maturity period. Such genotypes could vacate the field early, making possible the normal sowing of next Rabi crop. These short duration accessions also provide an opportunity to include another short duration crop in the current cropping system. Because of above characters, these accessions are most advantageous for saving the crop management inputs as well as to intensify cropping system. This would increase the benefit cost ratio and income of the farmers. The cultivars which flower at 60 days were considered most suitable to minimize the losses by insect and disease due to short flowering period. Khadi et al., (2010) also reported less damage of insect and pest in early maturing cultivars because they complete the boll formation before built up of insect populations. Venugopalan et al., (2014) have also reported the series of advantages of short duration variety in the form of higher yield, quality fibre, minimum cultivation cost with more profit, minimum management, water use efficiency, insecticide efficacy, minimize pesticide usage, uniformity, harvesting in one go manually or mechanically and also to gives farmer time to take another crop.

Similarly, in the accession of flowering period up to 80 days the value of each trait improved than the accession which flower at 60 days except ginning outturn which was observed almost same. The maturity period of the accession of this group ranged from 130-200 days but most of the accessions were of maturity period less than 170 days. The width of most of the accessions of this group was between 30 and $60 \mathrm{~cm}$. The accessions of this type of characteristic are semi spreading in nature. In the group of accessions which flower at 100 days, the maturity period ranged from 130 to more than 200 days, with majority between 150-180 days (Fig. 2). 
Table.1 Superior accessions for various traits in groups of different flowering period

\begin{tabular}{|c|c|c|c|c|c|c|c|c|c|c|c|c|}
\hline & $\begin{array}{l}\text { Superior } \\
\text { genotype }\end{array}$ & $\begin{array}{l}\text { Boll } \\
\text { weight(g) }\end{array}$ & $\begin{array}{l}\text { Superior } \\
\text { genotype }\end{array}$ & $\begin{array}{l}\text { Yield/ } \\
\text { plant (g) }\end{array}$ & $\begin{array}{l}\text { Superior } \\
\text { genotype }\end{array}$ & $\begin{array}{l}\text { Bolls/ } \\
\text { Plant }\end{array}$ & $\begin{array}{l}\text { Superior } \\
\text { genotype }\end{array}$ & $\begin{array}{l}\text { Ginning } \\
\text { outturn }\end{array}$ & $\begin{array}{l}\text { Superior } \\
\text { genotype }\end{array}$ & $\begin{array}{l}\text { seed } \\
\text { index }(\mathrm{g})\end{array}$ & $\begin{array}{l}\text { Superior } \\
\text { genotype }\end{array}$ & $\begin{array}{l}\text { lint } \\
\text { index }\end{array}$ \\
\hline 1 & IC 358823 & 3.6 & IC 358706 & 122.5 & SA 42 & 40 & IC 359065 & 40.6 & IC 356769 & 11.6 & IC 358862 & 6.2 \\
\hline 2 & S 4727-A-1 & 3.58 & IC 358920 & 120.02 & S 4727-A-1 & 38 & IC 359685 & 40.3 & IC 358728 & 11.0 & IC 359708 & 5.5 \\
\hline 3 & IC 358862 & 3.53 & IC 358016 & 118 & IC 358862 & 34 & IC 359708 & 40.0 & IC 357354 & 10.5 & IC 357170 & 5.2 \\
\hline Mean & & 2.9 & & 53.1 & & 17.01 & & 32.7 & & 8.5 & & 3.7 \\
\hline CD at $0.5 \%$ & & 0.1 & & 4.2 & & 1.1 & & 0.6 & & N/A & & N/A \\
\hline Range & & $1.4-3.6$ & & $\begin{array}{l}6.6- \\
122.5\end{array}$ & & $1-40$ & & $21.7-40.6$ & & $6.1-11.6$ & & $1-6.2$ \\
\hline \multicolumn{13}{|c|}{ Superior accessions in group of flowering period up to 80 days (188 numbers) } \\
\hline 1 & IC 356727 & 3.8 & AK 32 & 167.4 & C 3381 & 55 & IC 356667 & 40.3 & IC 356742 & 11.8 & IC 359484 & 7.0 \\
\hline 2 & IC 356754 & 3.7 & N 52 & 164 & AK 32 & 54 & IC 359599 & 39.9 & IC 357723 & 11.7 & N 66 & 6.7 \\
\hline 3 & IC 357242 & 3.7 & C 3381 & 154 & N 66 & 50 & IC 358865 & 39.8 & SA 744 & 11.2 & IC 356667 & 6.6 \\
\hline GM & & 3.0 & & 62.1 & & 19.21 & & 33.2 & & 8.5 & & 3.9 \\
\hline CD at $0.5 \%$ & & 0.1 & & 3.9 & & 1.6 & & 0.6 & & 0.3 & & NA \\
\hline Range & & $1.8-3.8$ & & $\begin{array}{l}5.0- \\
167.4\end{array}$ & & $1.0-55.0$ & & $25.0-40.3$ & & $5.6-11.8$ & & $1.0-7.0$ \\
\hline \multicolumn{13}{|c|}{ Superior accessions in group of flowering period up to 100 days (283 numbers) } \\
\hline 1 & IC 358753 & 3.8 & N 159 & 184.8 & Malcot -17 & 68 & IC 357591 & 40.9 & IC 357352 & 12.0 & IC 360029 & 6.8 \\
\hline 2 & IC 357147 & 3.8 & N $34 \mathrm{~B}$ & 182.4 & IC 359918 & 64 & IC 357856 & 40.3 & IC 356711 & 11.6 & SA 1334 & 6.5 \\
\hline 3 & SR 146 & 3.7 & HISAR 4 & 171.5 & IC 359919 & 54 & IC 359111 & 40.3 & SA 1334 & 11.0 & IC 359322 & 6.5 \\
\hline Mean & & 3.1 & & 68.7 & & 21.72 & & 33.1 & & 8.5 & & 3.8 \\
\hline CD at $0.5 \%$ & & 0.1 & & 6.2 & & 1.09 & & 0.5 & & 0.2 & & NA \\
\hline Range & & $1.4-3.8$ & & $\begin{array}{l}6.2- \\
184.8\end{array}$ & & $1.0-68.0$ & & $22.6-40.9$ & & $5.9-12.0$ & & $1-6.8$ \\
\hline \multicolumn{13}{|c|}{ Superior accessions in group of flowering period up to 120 days (287 numbers) } \\
\hline 1 & IC 356763 & 3.9 & EC 35560 & 190 & CNH 1025 & 65 & IC 358738 & 40.9 & SA 1406 & 12.0 & IC 359659 & 6.8 \\
\hline 2 & SA 1177 & 3.9 & DCI 234 & 180 & SV 504 & 63 & IC 359660 & 40.0 & SA 1395 & 11.2 & VC 8 & 6.6 \\
\hline 3 & IC 360013 & 3.8 & SV 504 & 175 & N 67 & 56 & IC 356799 & 440.0 & SA 1177 & 11.1 & IC 359969 & 6.5 \\
\hline Mean & & 3.1 & & 65.7 & & 21.49 & & 33.3 & & 8.5 & & 4.0 \\
\hline CD at $0.5 \%$ & & 0.1 & & 3.9 & & 0.62 & & 0.4 & & 0.4 & & 0.2 \\
\hline Range & & $1.8-3.9$ & & $8.0-190$ & & $1.0-65.0$ & & $25.0-40.9$ & & $5.6-12.0$ & & $1.0-6.8$ \\
\hline
\end{tabular}

$\mathrm{GM}=$ general mean; $\mathrm{CD}$ Crital difference at $0.5 \%$ 
Fig.1 Frequency of accession in different group of flowering period (days) and their maturity duration

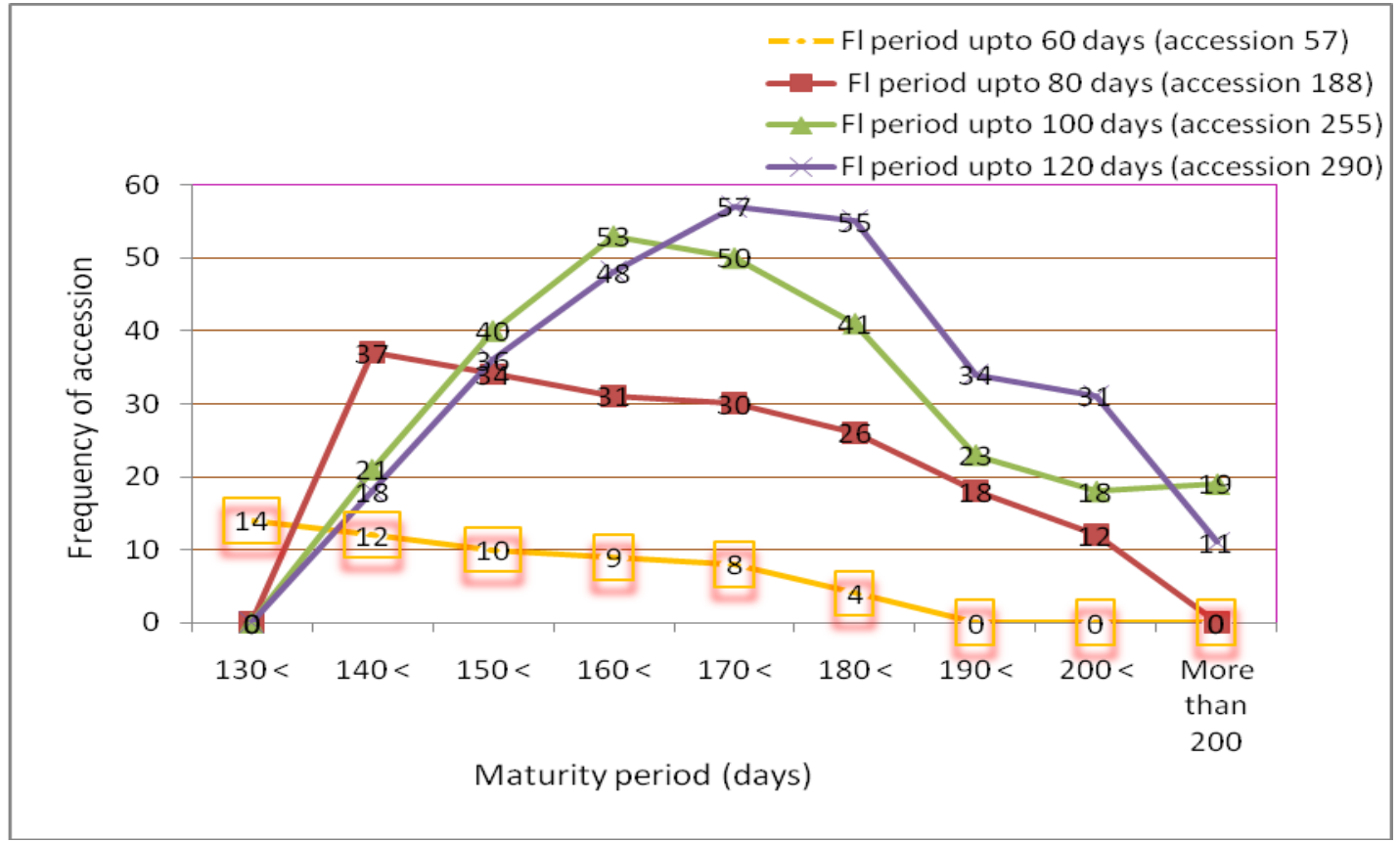

*Fl= flowering; Flowering frequency and horizontal plant width are the mean of two replications with two rows each.

Fig.2 Frequency of accession in different group of flowering period (days) and their horizontal width

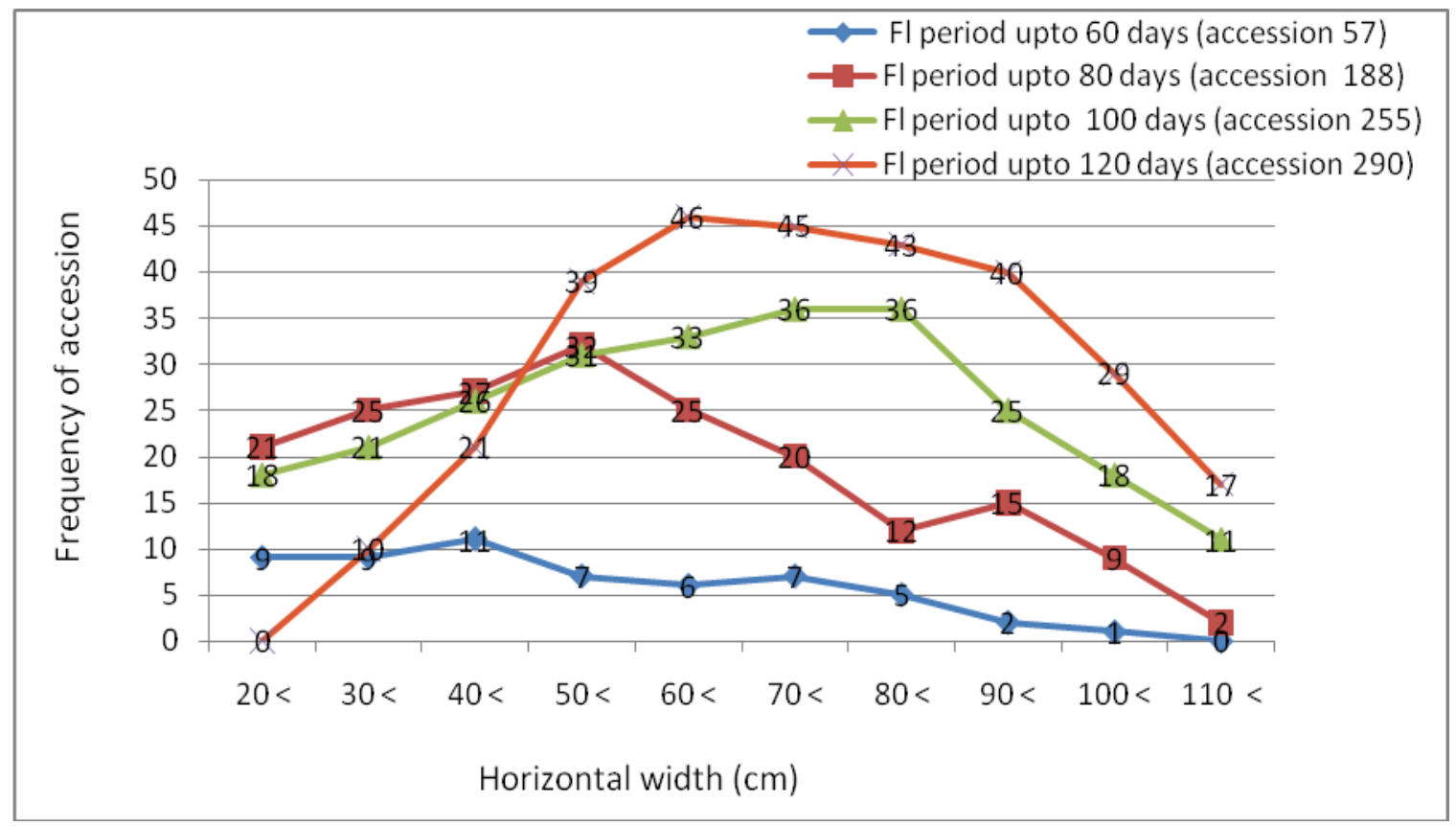

$* \mathrm{Fl}=$ flowering; Flowering frequency and horizontal plant width are the mean of two replications with two rows each. 
The horizontal width of these accessions was between 50 and $90 \mathrm{~cm}$. These accessions are spreading in nature and are suitable under normal-wider spacing. However, these accessions were considered most vulnerable to insect and disease due to long flowering period, thus require extra inputs and intensive management practices.

Under current cropping system, the cultivars which flower at 100 days should be preferred if the biotic and abiotic factors of crop losses can be effectively controlled. The accessions which flower after 120 days, have not showed any superiority with respect to the most of the traits except the slight increase in yield (Table 1). Even in superior accession of groups flower both at 100 days and 120 days, almost similar values of each trait were observed. The selection of the cultivars which flower at 120 days are not beneficial in term of boll weight, yield per plant, boll number per plant. In such accessions, the adequate water and pest control measures are required until boll maturity without much yield advantage. Such extra cost reduces the net benefit from the crop.

The maturity of most of the accession of this group was between 160-190 days. The width of the most of the accession was from 50-90 $\mathrm{cm}$ which makes the cultivars suitable for wider spacing. Hence, to maximize the net income to the farmer, the cultivars which flower at 100 days should be preferred incurrent cropping system.

In each group, some of the accessions found superior for a specific trait also possessed superiority for other traits in combinations. The accessions S-4727-A-1 and IC 358862 with flowering period upto 60 days have superiority for boll weight, number of bolls per plant and the accession IC 359708 for ginning out turn and lint index. Similarly, the accession AK 32 and C 3381 with flowering period up to 80 days, showed superiority for seed cotton yield/plant as well as for number of bolls plant while accession N -66 for number of bolls per plant and lint index and accession IC 356667 for ginning out turn and lint index. In the group of flowering up to 120 days, the accession SA 1177 for boll weight and seed index and accession SV 504 for yield/plant and boll number/plant possessing the superiority. This accession should be used in further crop improvement programmes depending upon the requirement and the climatic situation.

The further breeding improvement programme should be concentrated on utilizing the accession which flower at 60 days to develop the cultivars suitable for HDPS for maximizing the yield without much crop inputs. These accessions are fit for the regions in the world, having the climatic condition similar to North Zone of India.

The cultivars which flower late require extra input of water and pesticide, thus reduces the cost benefit ratio. Hence, to maximize the net income of the cotton farmer, the cultivars which flower at 60 days should be preferred.

Presently, the long duration cultivars are being cultivated in most of the cotton growing areas of the world, however, the longer duration of the cotton crop poses many threats including insect pest and disease attack to the crop. The accessions which flower late did not provide additional benefit in terms of boll weight, yield per plant, boll number per plant than the accessions which flower early, rather they require a lot crop production and crop protection inputs. In the present study, the short listed accessions which flower early (60-80 days) and having maturity below 150 days with horizontal width around $40 \mathrm{~cm}$ found superior. In addition to this, these accessions are suitable for HDPS, and require less input of water and pesticides which 
enhance the cost benefit ratio for the farmers. Hence, to maximize the net income of the cotton farmer, these accessions could be used for further crop improvement programmes.

\section{Conflict of interest}

On behalf of all authors, first author declares that they have no conflict of interest. The work described in the paper has not been published before; that it is not under consideration for publication anywhere else; that its publication has been approved by all co-authors, as well as by the responsible authorities - tacitly or explicitly - at the institute where the work has been carried out. The publisher will not be held legally responsible should there be any claims for compensation. All authors are wishing to include figures, tables, or text passages that have not been published elsewhere.

\section{Contribution of authors}

RAM, DM, SLA conceived and designed research. RAM conducted experiments and analyzed data. RAM, DM, and SKS compiled the information and wrote the manuscript. All authors read and approved the manuscript.

\section{Acknowledgments}

The authors are thankful Indian Council for Agricultural Research-Central Institute for Cotton Research, Regional Station, Sirsa under Indian Council of Agricultural Research, New Delhi for providing necessary laboratory and field facilities and funding during the course of the investigation.

\section{References}

Anonnymous. (2017). All India Coordinated Cotton Improvement Project Report. PP A3-A5.

Hinze, L. L., Kohel, R. J., Campbell, B.T., and Percy, R. G. (2011). Variability in four diverse cotton (Gossypium hirsutum L.) germplasm populations. Genetics Research and Crop Evoluation. 58(4):561-570.

Khadi, B. M., Santhy, V. and and Yadav, M, S. (2010). Cotton- An introduction. In: Cotton Biotechnological Advances. (Ed) Zehr, U.B. Spinger Publication Ltd. p 114.

Sheoran, O. P., Tonk, D. S., Kaushik, L. S., Hasija, R.C. and Pannu, R.S. (1998). Statistical Software Package for Agricultural Research Workers. In: Hooda, D S, Hasija RC. (Eds.), Recent Advances in information theory, Statistics and Computer Applications. Published by Department of Mathematics Statistics, CCS HAU, Hisar, India, pp.139-143.

Talib, I., Ali, S., Pervez, M. W., Hassan, M. U., Hussain, R., Rehman K, Firdous, R. and Hussain, S. (2015). Study of genetic diversity in germplasm of upland cotton (Gossypium hirsutum L.) in Pakistan. American Journal of Plant Sciences 6: 2161-2167

Venugopalan, M. V., Kranthi, K. R., Blaise, D., Lakde, S. and Sankaranarayana, K. (2014). High density planting system in cotton - The Brazil Experience and Indian Initiatives. Cotton Research Journal. 5(2): $1-7$

\section{How to cite this article:}

Ram Awatar Meena, Dilip Monga, Satish Kumar Sain and Shankar Lal Ahuja. 2018. Flowering Period Variability in Relation to Seed Cotton Yield, Ginning Out Turn and Other Desirable Traits in Genetic Resources of G.hirsutum Cotton. Int.J.Curr.Microbiol.App.Sci. 7(10): 1678-1685. doi: https://doi.org/10.20546/ijcmas.2018.710.192 